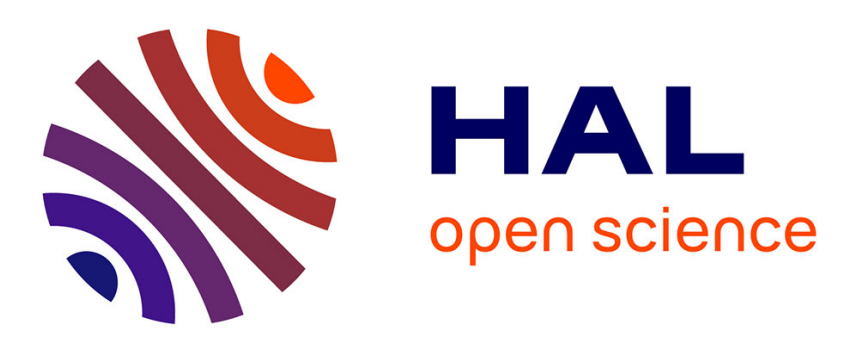

\title{
Improving structural features of nanoporous alumina using deuterated electrolytes
}

Anastasia Christoulaki, Chiara Moretti, Alexis Chennevière, Emmanuelle Dubois, Nicolas Jouault

\section{- To cite this version:}

Anastasia Christoulaki, Chiara Moretti, Alexis Chennevière, Emmanuelle Dubois, Nicolas Jouault. Improving structural features of nanoporous alumina using deuterated electrolytes. Microporous and Mesoporous Materials, 2020, 303, 10.1016/j.micromeso.2020.110201 . hal-02878778

\section{HAL Id: hal-02878778 \\ https: / hal.sorbonne-universite.fr/hal-02878778}

Submitted on 23 Jun 2020

HAL is a multi-disciplinary open access archive for the deposit and dissemination of scientific research documents, whether they are published or not. The documents may come from teaching and research institutions in France or abroad, or from public or private research centers.
L'archive ouverte pluridisciplinaire HAL, est destinée au dépôt et à la diffusion de documents scientifiques de niveau recherche, publiés ou non, émanant des établissements d'enseignement et de recherche français ou étrangers, des laboratoires publics ou privés. 


\section{Graphical Abstract}

Improving structural features of nanoporous alumina using deuterated electrolytes

Anastasia Christoulaki, Chiara Moretti, Alexis Chennevière, Emmanuelle Dubois, Nicolas Jouault

Nanoporous alumina

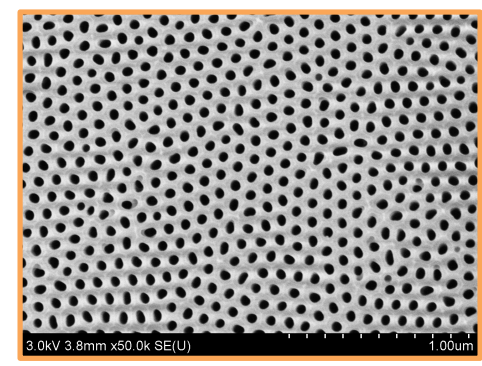

synthesis

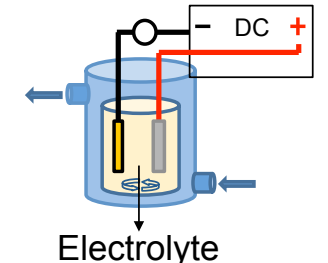

$\mathrm{H}_{2} \mathrm{O}$
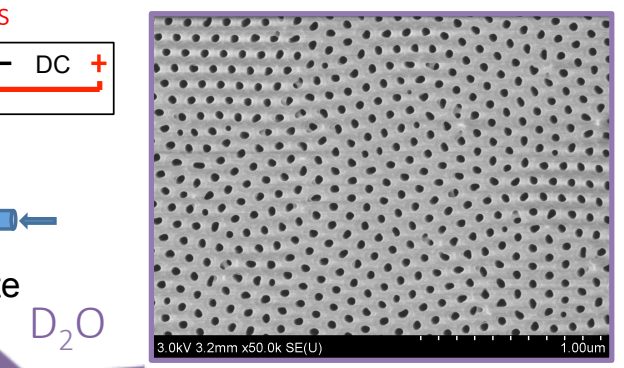

$\checkmark$ Better pore ordering

$\checkmark$ Smaller pore diameter

$\checkmark$ Improved growth rate 


\section{Highlights}

\section{Improving structural features of nanoporous alumina using deuter- ated electrolytes}

Anastasia Christoulaki, Chiara Moretti, Alexis Chennevière, Emmanuelle Dubois, Nicolas Jouault

- Nanoporous alumina have been synthesized using deuterated electrolytes.

- The pore diameter reached with deuterated electrolytes is as small as the smallest pore size obtained so far in the literature.

- A better hexagonal pore ordering is observed and correlated to an increase in anion incorporation.

- The pore growth rate is improved and related to a decrease in the activation energy of the alumina formation.

- Thanks to the sensitivity of Small-Angle Neutron Scattering to deuteration, the use of deuterated electrolytes allows discussing the presence or not of $\mathrm{OH}$ groups within the material. 


\title{
Improving structural features of nanoporous alumina using deuterated electrolytes
}

\author{
Anastasia Christoulaki ${ }^{\mathrm{a}}$, Chiara Moretti ${ }^{\mathrm{a}}$, Alexis Chennevière ${ }^{\mathrm{b}}$, \\ Emmanuelle Dubois ${ }^{a}$, Nicolas Jouaulta,* \\ ${ }^{a}$ Sorbonne Université, CNRS, Laboratoire Physicochimie des Electrolytes et des \\ Nanosystèmes Interfaciaux, PHENIX, F-75005 Paris, France. \\ ${ }^{b}$ Laboratoire Léon Brillouin, Université Paris-Saclay, CEA-CNRS, Saclay, 91191 \\ Gif-sur-Yvette CEDEX, France.
}

\begin{abstract}
Nanoporous anodic aluminum oxides (AAOs) are well-known nanoporous materials with multiple applications. In the last years new experimental strategies have been developed to produce AAOs in order to tune the pore morphology or ordering and discuss the AAOs growth mechanism. Here we describe an original approach to synthesize AAOs using deuterated electrolytes (i.e. sulfuric or oxalic acids in deuterated water $\mathrm{D}_{2} \mathrm{O}$ ) leading to a pore diameter reduction of around $20 \%$ and an increase in the pore ordering and pore growth. Better pore ordering in $\mathrm{D}_{2} \mathrm{O}$ is correlated to an increase in anion incorporation during the synthesis and the growth rate improvement is related to a decrease in the activation energy of the alumina formation. Moreover, the use of deuterated species allows to discuss the incorporation of hydroxyl groups during the AAO synthesis or the hydration after immersion in $\mathrm{H}_{2} \mathrm{O}$ or $\mathrm{D}_{2} \mathrm{O}$ by Small-Angle Neutron Scattering (SANS), a technique
\end{abstract}

\footnotetext{
${ }^{*}$ Corresponding author

Email address: nicolas.jouault@sorbonne-universite.fr (Nicolas Jouault)
} 
sensitive to deuteration. SANS reveals no changes between AAOs synthesized in $\mathrm{H}_{2} \mathrm{O}$ or $\mathrm{D}_{2} \mathrm{O}$ due to $\mathrm{OH}$ incorporation but shows differences after a long immersion time in water $\left(\mathrm{H}_{2} \mathrm{O}\right.$ or $\left.\mathrm{D}_{2} \mathrm{O}\right)$, indicating that the hydration is a slow process. This work shows that the use of deuterium is an interesting alternative for the synthesis of AAOs with well-controlled and specific morphologies and, from a fundamental point of view, can bring new general understanding about AAOs formation.

Keywords: Nanoporous alumina, Synthesis, Deuterated electrolytes, Pore ordering, Small-Angle Neutron Scattering

\section{Introduction}

Nanoporous anodic alumina oxides (AAOs) consist of parallel nanochannels with pore diameter $\left(\mathrm{D}_{p}\right)$, interpore distance $\left(\mathrm{D}_{\text {int }}\right)$, length $(\mathrm{L})$ and porosity $(\mathrm{P})$ perfectly tunable through the synthesis conditions. Thanks to the versatility of the obtained morphology, AAOs became very popular nanomaterials and are currently used in many applications such as confining medium[1], sensors[2] or templates[3]. AAOs are synthesized by the anodization of pure aluminum in acidic electrolytes under potentiostatic (constant voltage) or galvanostatic (constant current) conditions. In 1995, Masuda and Fukuda proposed an experimental approach to obtain well-ordered nanopores organization thanks to a two-step anodizations synthesis under conventional conditions called "mild anodization" (named MA, corresponding to the use of a moderate temperature and moderate voltage giving a typical growth rate (GR) below $10 \mu \mathrm{m} / \mathrm{h}$ )[4]. Later, hard anodization (HA) was proposed to increase the GR (around $50 \mu \mathrm{m} / \mathrm{h}$ ) by making the synthesis with higher 
voltage (above the voltage breakdown) by working at low temperature (below $\left.0^{\circ} \mathrm{C}\right)[5]$. In such conditions, HA usually leads to the formation of larger pores $(>100 \mathrm{~nm}$ ) and higher interpore distance (from 200 to $500 \mathrm{~nm}$ ) with, compared to MA, different linear evolution with the voltage[6]. For both MA and HA the classical electrolytes used are sulfuric, oxalic or phosphoric acids but various other dicarboxylic acid electrolytes have been also used such as malonic, tartronic, maleic, tartaric, or citric acids[7].

In the last years, a particular attention has been drawn on the optimization of AAOs synthesis in order to tune the pore morphology, pore ordering and GR. New experimental protocols involving new electrolytes or new anodization conditions have been explored. For example, the smallest pore diameter has been reached by using selenic acid (around $10 \mathrm{~nm}$ with low pore density and aspect ratio after $1 \mathrm{~h}$ anodization)[8] or concentrated sulfuric acid (around $15 \mathrm{~nm}$ for higher pore density and a total thickness of $50 \mu \mathrm{m})[9]$. Increasing the electrolyte concentration also leads to an increase of pore self-ordering, as observed for AAOs synthesized with concentrated oxalic acid[10]. Besides, a smaller $\mathrm{D}_{p}$, accompanied with a lower $\mathrm{GR}$, is observed when adding a certain amount of polyethylene glycol to phosphoric acid. This additive increases the viscosity and decreases the acidity of the electrolyte mixtures, reducing $\mathrm{D}_{p}$ from $200 \mathrm{~nm}$ to $100 \mathrm{~nm}[11]$. Other authors showed that, in glycerol solution of oxalic acid, the AAOs thicknesses are linearly dependent on the inverse of electrolyte viscosity[12], confirming the GR decrease when using more viscous electrolyte. On the contrary, ethanol and ionic liquids have been used to increase the GR. Qin et al. found that $10 \%$ of ethanol can increase the GR by a factor of 5 with a $\mathrm{D}_{p}$ of $15 \mathrm{~nm}$ while keep- 
ing the voltage low $(25 \mathrm{~V})[13]$. However, the addition of more ethanol has the reverse effect, i.e. decrease the GR. Similarly Salerno et al. showed that the use of ionic liquids (from 0.01 to $1 \% \mathrm{v} / \mathrm{v}$ of 1-Butyl-3-methylimidazolium 2-(2-methoxyethoxy) ethyl sulfate and 1-Butyl-3-methylimidazolium tetrafluoborate) in $0.03 \mathrm{M}$ oxalic acid under galvanostatic conditions also increases the GR by a factor of 3.5[14].

In this context, we propose an original approach for the AAO synthesis using deuterated solvent (heavy water, $\mathrm{D}_{2} \mathrm{O}$ ) and/or deuterated acids (such as deuterated sulfuric acid, $\left.\mathrm{D}_{2} \mathrm{SO}_{4}\right)$. The use of deuterated species has not been fully exploited, while it can provide valuable information, in particular on the structural AAO features. So far, few works involved deuterated species for AAOs synthesis[15, 16] and none investigated the morphologies of AAOs prepared with deuterated electrolytes but focused on the possible AAO hydration during the synthesis. Indeed, under the high electric field generated during the anodization, water dissociates in $\mathrm{O}^{2-}$ and $/$ or $\mathrm{OH}^{-}$migrating inside the oxide and forming with $\mathrm{Al}^{3+}$ alumina $\left(\mathrm{Al}_{2} \mathrm{O}_{3}\right)$ or aluminum hydroxydes such as $\mathrm{AlOOH}$ (boehmite) or $\mathrm{Al}(\mathrm{OH})_{3}$ (bayerite) depending on the $\mathrm{OH}^{-}$quantity $[17,18]$. By using deuterated species, one substitutes $\mathrm{D}$ for $\mathrm{H}$ and can probe the presence (or not) of D within the structure. Dorsey used deuterated electrolytes to elucidate the hydration of the anodic films by infrared absorption spectroscopy[15] probing shifts in bands to lower wavenumbers in AAOs synthesized in deuterated sulfuric acids. Lu and coworkers[16] studied the diffusion of $\mathrm{H} / \mathrm{D}$ through the barrier layer in thin films synthesized on Si wafers by Secondary Ion Mass Spectroscopy and observed the deuterium incorporation into $\mathrm{AAO}$ and at the $\mathrm{Si} / \mathrm{AAO}$ interface. In this pa- 
per, we investigate the influence of deuterium (D) i) on the structural pore organization, morphology and GR and ii) gain understanding on the chemical composition (anion incorporation and possible hydration) of AAOs by coupling Energy Dispersive Spectroscopy (EDS) and Small Angle Neutron Scattering (SANS), the latter being very sensitive to deuteration substitution.

\section{Experimental methods}

\subsection{AAOs preparation}

Herein, AAOs are prepared using the classical two-step anodizations using different sulfuric or oxalic based electrolytes at a fixed concentration of $0.3 \mathrm{M}$ : deuterated sulfuric acid in $\mathrm{D}_{2} \mathrm{O}$ (named $\mathrm{D}_{2} \mathrm{SO}_{4} / \mathrm{D}_{2} \mathrm{O}$ ), hydrogenated sulfuric acid in $\mathrm{D}_{2} \mathrm{O}\left(\mathrm{H}_{2} \mathrm{SO}_{4} / \mathrm{D}_{2} \mathrm{O}\right)$, hydrogenated sulfuric acid in $\mathrm{H}_{2} \mathrm{O}\left(\mathrm{H}_{2} \mathrm{SO}_{4} / \mathrm{H}_{2} \mathrm{O}\right)$ and oxalic acid $\left(\mathrm{OA}, \mathrm{H}_{2} \mathrm{C}_{2} \mathrm{O}_{4}\right)$ in $\mathrm{H}_{2} \mathrm{O}$ or $\mathrm{D}_{2} \mathrm{O}$. Table $\mathrm{S} 1$ summarizes the different physical and chemical parameters of the different electrolytes used in this work. One can notice a $\mathrm{pH}$ increase and a conductivity decrease in $\mathrm{D}_{2} \mathrm{O}$, in good agreement with the weaker acid dissociation already observed in the literature. A first anodization is carried out during 2 hours (h) at a constant temperature (from $4^{\circ} \mathrm{C}$ to $20^{\circ} \mathrm{C}$ for sulfuric and $18^{\circ} \mathrm{C}$ for oxalic

electrolytes) and constant applied voltage (20 V and $40 \mathrm{~V}$ for sulfuric and oxalic acid, respectively). Note that the breakdown voltage was found to be $21 \mathrm{~V}$ in sulfuric $/ \mathrm{D}_{2} \mathrm{O}$ electrolyte while it is $27 \mathrm{~V}$ in sulfuric $/ \mathrm{H}_{2} \mathrm{O}$. The formed oxide is then chemically dissolved in phosphochromic acid solution (6 wt\% $\mathrm{H}_{3} \mathrm{PO}_{4}$ and $1.8 \mathrm{wt} \% \mathrm{CrO}_{3}$ ) during $2 \mathrm{~h}$ at $60^{\circ} \mathrm{C}$. Finally, a second anodization is performed under the same conditions as the first one during a chosen time 
(typically from $1 \mathrm{~h}$ to $8 \mathrm{~h}$ ).

\subsection{Scanning Electron Microscopy (SEM) and Energy Dispersive spectroscopy $(E D S)$}

The AAOs were characterized by Scanning Electron Microscopy (SEM) to access the pore morphology and ordering. SEM imaging were performed on a field emission gun scanning electron microscope (FEGSEM, SU-70 Hitachi) at an accelerating voltage of $3 \mathrm{kV}$ and images with different magnifications (x10000, x20000, x50000 and x100000) have been recorded. Energy Dispersive spectroscopy (EDS) has been performed with an OXFORD X-Max SDD for elemental analysis (Al, O, C and $\mathrm{S}$ elements) at $5 \mathrm{kV}$ on different areas of uncoated samples after calibration with a silicon standard.

\subsection{Small-Angle Neutron Scattering (SANS)}

Small-Angle Neutron Scattering (SANS) experiments have been performed on PAXY spectrometer (Laboratoire Léon Brillouin, LLB CEA Saclay) and D11 spectrometer (Institut Laue Langevin, ILL). On PAXY, four configurations were used: $6.7 \mathrm{~m} / 15 \AA, 5 \mathrm{~m} / 8.5 \AA, 3 \mathrm{~m} / 5 \AA, 1 \mathrm{~m} / 5 \AA$ covering a q range from $2.10^{-3} \AA^{-1}$ to $0.5 \AA^{-1}$ and data reduction was performed with homemade PASINET software. On D11, four configurations were used: $39 \mathrm{~m} / 6 \AA$, $16 \mathrm{~m} / 6 \AA, 8 \mathrm{~m} / 6 \AA, 1.4 \mathrm{~m} / 6 \AA$ covering a $\mathrm{q}$ range from $2.10^{-3} \AA^{-1}$ to $0.4 \AA^{-1}$ (data available in ref[19]) and data reduction was performed with ILL GRASP software[20]. The AAOs are aligned along the neutron beam and immersed into $\mathrm{H}_{2} \mathrm{O} / \mathrm{D}_{2} \mathrm{O}$ mixtures $\left(73.2 \%\right.$ or $\left.75.5 \% \mathrm{D}_{2} \mathrm{O}\right)$ to avoid multiple scattering effects. We recently described a detailed methodology to measure AAOs by SANS[21] and here we will only provide the necessary information for the 
basic understanding of the data interpretation. From SANS, we measure the scattering intensity $\mathrm{I}(\mathrm{q})$ from which information about the structure and chemical composition can be extracted through the complete fitting of the experimental data. The intensity depends on the averaged scattering amplitude of the object form $<\mathrm{F}(\mathrm{q})>$ and the structure factor $\mathrm{S}(\mathrm{q})$. For the latter, a hard sphere (HS) or hexagonal (HEX) model[22, 21] have been used depending on the degree of ordering. Then, the F(q) can be reproduced by a core/shell model, the core being the pore filled with the solvent and the shell being the contaminated layer (see below). The composition is accessed by the scattering length density (SLD, noted $\rho$ in the model) that depends on the chemical formula and the density of the materials. In our recent work, we also pointed out the importance of the length implemented in the fitting model corresponding to the longitudinal correlation length $\mathrm{L}_{z}$ (which is not equivalent to the real AAO length). $\mathrm{L}_{z}$ is determined by measuring the scattering intensity variation at the $\mathrm{Q}_{10}$ peak position as a function of the tilting angle along the pore axis. By doing so we obtained a rocking curve from which $\mathrm{L}_{z}$ is calculated (see as an example in Figure S1 the rocking curve of AAO synthesized in $\left.\mathrm{OA} / \mathrm{H}_{2} \mathrm{O}\right)$. In the following the SANS data will be presented with the best fits given by the model and the fitting parameters will be listed in a table. 


\section{Results and Discussion}

\subsection{Influence of deuterated electrolytes on structural organization and growth rate}

\subsubsection{Pore diameter and ordering}

Fig.1a shows SEM images of AAOs top surface synthesized in $\mathrm{D}_{2} \mathrm{SO}_{4} / \mathrm{D}_{2} \mathrm{O}$, $\mathrm{H}_{2} \mathrm{SO}_{4} / \mathrm{D}_{2} \mathrm{O}$ and $\mathrm{H}_{2} \mathrm{SO}_{4} / \mathrm{H}_{2} \mathrm{O}$ at $\mathrm{T}=10{ }^{\circ} \mathrm{C}$ under $20 \mathrm{~V}$ during $8 \mathrm{~h}$. Image analysis give similar pore densities but different mean $\mathrm{D}_{p}$ of $20+/-3 \mathrm{~nm}, 16+/-3$ $\mathrm{nm}$ and $16+/-3 \mathrm{~nm}$ for $\mathrm{H}_{2} \mathrm{SO}_{4} / \mathrm{H}_{2} \mathrm{O}, \mathrm{H}_{2} \mathrm{SO}_{4} / \mathrm{D}_{2} \mathrm{O}$ and $\mathrm{D}_{2} \mathrm{SO}_{4} / \mathrm{D}_{2} \mathrm{O}$, respectively, corresponding to a $\mathrm{D}_{p}$ decrease of around $20 \%$ when using deuterated water with no significant changes in the pore diameter dispersity (see Table 1). The use of $\mathrm{H}_{2} \mathrm{SO}_{4}$ or $\mathrm{D}_{2} \mathrm{SO}_{4}$ with $\mathrm{D}_{2} \mathrm{O}$ doesn't modify the $\mathrm{D}_{p}$, indicating that even a small H content within the electrolyte doesn't influence the pore morphology. When anodizing during a shorter time $(2 \mathrm{~h})$ the $\mathrm{D}_{p} \mathrm{~s}$ are smaller (around $12.5 \mathrm{~nm}$, see Fig. 1b) and remain similar whatever the electrolyte used, indicating that the pore dissolution is time and electrolyte dependent. The dissolution rate is enhanced in hydrogenated electrolyte after a long time (1.1 nm/h and $0.6 \mathrm{~nm} / \mathrm{h}$ for $\mathrm{H}_{2} \mathrm{SO}_{4} / \mathrm{H}_{2} \mathrm{O}$ and $\mathrm{D}_{2} \mathrm{SO}_{4} / \mathrm{D}_{2} \mathrm{O}$, respectively) and this effect is attributed to a stronger acidity of the hydrogenated electrolyte (i.e. having more $\mathrm{H}^{+}$, see $\mathrm{pH}$ and conductivity values in Table $\mathrm{S} 1$ ).

Moreover, if we focus on $\mathrm{D}_{2} \mathrm{SO}_{4} / \mathrm{D}_{2} \mathrm{O}$ electrolytes, the SEM images analysis showed a slight increase of pore diameter up to $15^{\circ} \mathrm{C}$ and a more pronounced increase at $20^{\circ} \mathrm{C}$ (Fig. 1c, blue squares). More interestingly one can reach a $\mathrm{D}_{p}$ of $11+/-3 \mathrm{~nm}$ for $1 \mathrm{~h}$ anodization, reaching a pore size similar to the smallest ones obtained up to now by using selenic acid[8] but with a higher aspect ratio and pore density, structural features very interesting for 

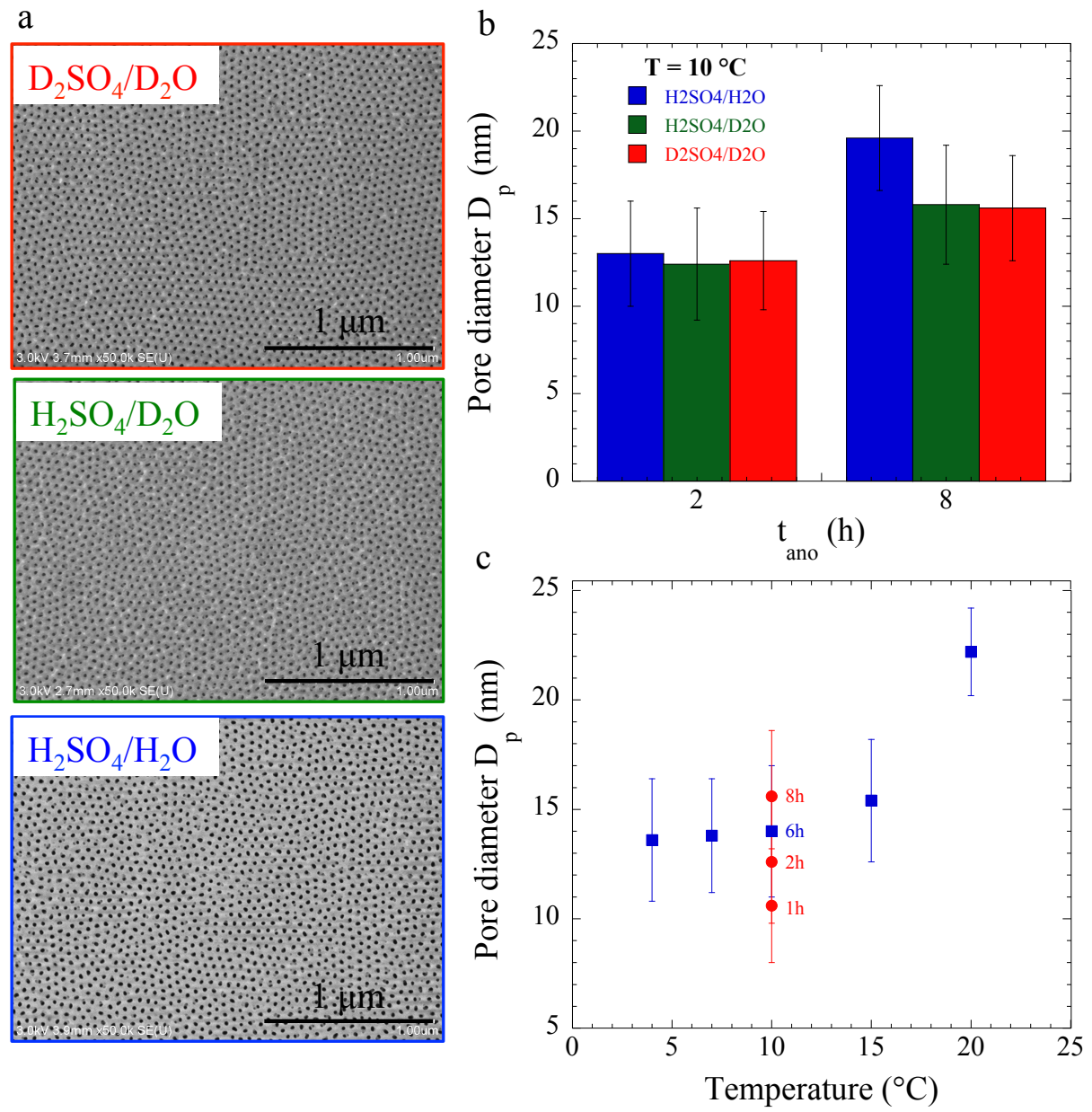

Figure 1: SEM images of AAO top surface prepared with $\mathrm{D}_{2} \mathrm{SO}_{4} / \mathrm{D}_{2} \mathrm{O}$ (red), $\mathrm{H}_{2} \mathrm{SO}_{4} / \mathrm{D}_{2} \mathrm{O}$ (green) and $\mathrm{H}_{2} \mathrm{SO}_{4} / \mathrm{H}_{2} \mathrm{O}$ (blue). Scale bar: $1 \mu \mathrm{m}$. (b) Pore diameter $\mathrm{D}_{p}$ for the three systems after $2 \mathrm{~h}$ and $8 \mathrm{~h}$ anodization. (c) $\mathrm{D}_{p}$ evolution with temperature at a given anodization time ( $6 \mathrm{~h}$, blue squares) and with time at a given temperature $\left(10^{\circ} \mathrm{C}\right.$, red circles) for AAOs synthesized in $\mathrm{D}_{2} \mathrm{SO}_{4} / \mathrm{D}_{2} \mathrm{O}$. 
Table 1: Structural parameters obtained from SEM analysis (pore size distribution and $\mathrm{S}(\mathrm{q})$ ) of the AAOs synthesized in sulfuric electrolytes during $8 \mathrm{~h}$ and oxalic electrolytes during 11h30: pore diameter $\mathrm{D}_{p}$, length $\mathrm{L}$ (one side), pore density $\mathrm{n}$, porosity, interpore distance $\mathrm{D}_{\text {int }}, \mathrm{D}_{\text {int }}$ standard deviation $\sigma_{\text {int }}$, grain size D. ${ }^{*}$ For $\mathrm{H}_{2} \mathrm{SO}_{4} / \mathrm{H}_{2} \mathrm{O}$ the $\mathrm{S}(\mathrm{q})$ is fitted with a hard sphere model giving an ordering parameter $\eta$. Also the grain size cannot be determined with this model ( $\mathrm{NA}=$ Non Available).

\begin{tabular}{cccccc} 
Electrolytes & $\mathrm{H}_{2} \mathrm{SO}_{4} / \mathrm{H}_{2} \mathrm{O}$ & $\mathrm{H}_{2} \mathrm{SO}_{4} / \mathrm{D}_{2} \mathrm{O}$ & $\mathrm{D}_{2} \mathrm{SO}_{4} / \mathrm{D}_{2} \mathrm{O}$ & $\mathrm{OA} / \mathrm{H}_{2} \mathrm{O}$ & $\mathrm{OA} / \mathrm{D}_{2} \mathrm{O}$ \\
\hline $\mathrm{j}\left(\mathrm{mA} \cdot \mathrm{cm}^{-2}\right)$ & 1.7 & 2.6 & 2.9 & 4.0 & 3.2 \\
\hline $\mathrm{D}_{p}(\mathrm{~nm})$ & $20+/-3$ & $16+/-3$ & $16+/-3$ & $55+/-3$ & $44+/-3$ \\
\hline $\mathrm{L}(\mu \mathrm{m})$ & 23 & 27 & 36 & 84 & 60 \\
\hline $\mathrm{GR}(\mu \mathrm{m} / \mathrm{h})$ & 2.9 & 3.4 & 4.5 & 7.3 & 5.2 \\
\hline $\mathrm{n}\left(10^{10} \mathrm{~cm}^{-2}\right)$ & 4.4 & 4.5 & 4.2 & 1.1 & 1.1 \\
\hline Porosity $(\%)$ & 16 & 12 & 9 & 26 & 16 \\
\hline $\mathrm{D}_{\text {int }}(\mathrm{nm})$ & 52.6 & 52.8 & 52.7 & 100 & 103 \\
\hline$\eta^{*} / \sigma_{\text {int }}$ & $0.49 /-$ & $-/ 0.098$ & $-/ 0.084$ & $-/ 0.06$ & $-/ 0.06$ \\
\hline Grain size $(\mathrm{nm})$ & $\mathrm{NA}$ & 314 & 370 & 714 & 997
\end{tabular}

applications such as molecular filtration or the preparation of nanostructures by templating approach[23].

Then, the pore ordering is quantified by performing the 2D Fast Fourrier Transform (FFT) of the pore centers in order to compute the structure factor $\mathrm{S}(\mathrm{q})$ as shown in Fig.2a for $\mathrm{H}_{2} \mathrm{SO}_{4} / \mathrm{H}_{2} \mathrm{O}$ (blue), $\mathrm{H}_{2} \mathrm{SO}_{4} / \mathrm{D}_{2} \mathrm{O}$ (green) and $\mathrm{D}_{2} \mathrm{SO}_{4} / \mathrm{D}_{2} \mathrm{O}$ (red). The $\mathrm{S}(\mathrm{q})$ gives information about the pore ordering and can be reproduced by different models depending on the ordering degree (see reference [21] for complete mathematical expressions). The $\mathrm{S}(\mathrm{q})$ of AAOs synthesized in $\mathrm{D}_{2} \mathrm{O}$ show clear peaks at intermediate $\mathrm{q}\left(\mathrm{q}_{11}\right.$ and $\left.\mathrm{q}_{20}\right)$ coming from a better pore organization and can be fitted with a 2D hexagonal model. 
On the contrary the $\mathrm{S}(\mathrm{q})$ of AAOs synthesized in $\mathrm{H}_{2} \mathrm{O}$ cannot be reproduced by the same model and is fitted with a hard sphere model indicating that the pores adopt a more disordered organization (the fitting parameters are also listed in Table 1). A hexagonal grain size cannot be extracted in $\mathrm{H}_{2} \mathrm{O}$ while a transverse hexagonal domain size of $370 \mathrm{~nm}$ is obtained in $\mathrm{D}_{2} \mathrm{O}$. Focusing only on the $\mathrm{D}_{2} \mathrm{SO}_{4} / \mathrm{D}_{2} \mathrm{O}$ AAOs synthesized at different temperatures, the $\mathrm{S}(\mathrm{q})$ analysis in Fig.2b shows quite similar ordering between $4{ }^{\circ} \mathrm{C}$ and 15 ${ }^{\circ} \mathrm{C}$ and a slightly better ordering at $20{ }^{\circ} \mathrm{C}$ (smaller $\sigma_{\text {int }}$ and a larger grain size, see Table S2). We can also notice that the anodization time (up to 8 h) doesn't modify the ordering as observed recently for AAOs prepared with oxalic acid[21].

Similar analyses have been performed for AAOs synthesized in $0.3 \mathrm{M}$ OA. Fig.3a and 3b show the SEM images of AAOs prepared in $\mathrm{H}_{2} \mathrm{O}$ and $\mathrm{D}_{2} \mathrm{O}$, respectively, and Fig.3c shows the corresponding $\mathrm{S}(\mathrm{q})$ derived from the images analysis and both fitted with an hexagonal model. Similar trends are observed in oxalic electrolyte: $\mathrm{D}_{p}$ decreases by around $20 \%$ in $\mathrm{D}_{2} \mathrm{O}$ (from $55 \mathrm{~nm}$ in $\mathrm{H}_{2} \mathrm{O}$ to $44 \mathrm{~nm}$ in $\left.\mathrm{D}_{2} \mathrm{O}\right)$ and the grain size increases from $714 \mathrm{~nm}$ in $\mathrm{H}_{2} \mathrm{O}$ to $997 \mathrm{~nm}$ in $\mathrm{D}_{2} \mathrm{O}$ (around $40 \%$ increase, see Table 1 ).

First, it has been observed that the best self-ordered pore structure is obtained for anodization performed just below the breakdown potential $\mathrm{U}_{B}$, corresponding to the voltage at which burning phenomena occur[24]. $\mathrm{U}_{B}$ depends on the anodized metal (here $\mathrm{Al}$ ), current density, electrolyte resistivity and composition of the oxide[6]. For $\mathrm{H}_{2} \mathrm{SO}_{4} / \mathrm{H}_{2} \mathrm{O}, \mathrm{U}_{B}=27 \mathrm{~V}$ and, in this work, we experimentally found that in $\mathrm{D}_{2} \mathrm{O} \mathrm{U}_{B}=21 \mathrm{~V}$, close to our applied voltage of $20 \mathrm{~V}$. The apparent increase of ordering can be related to 

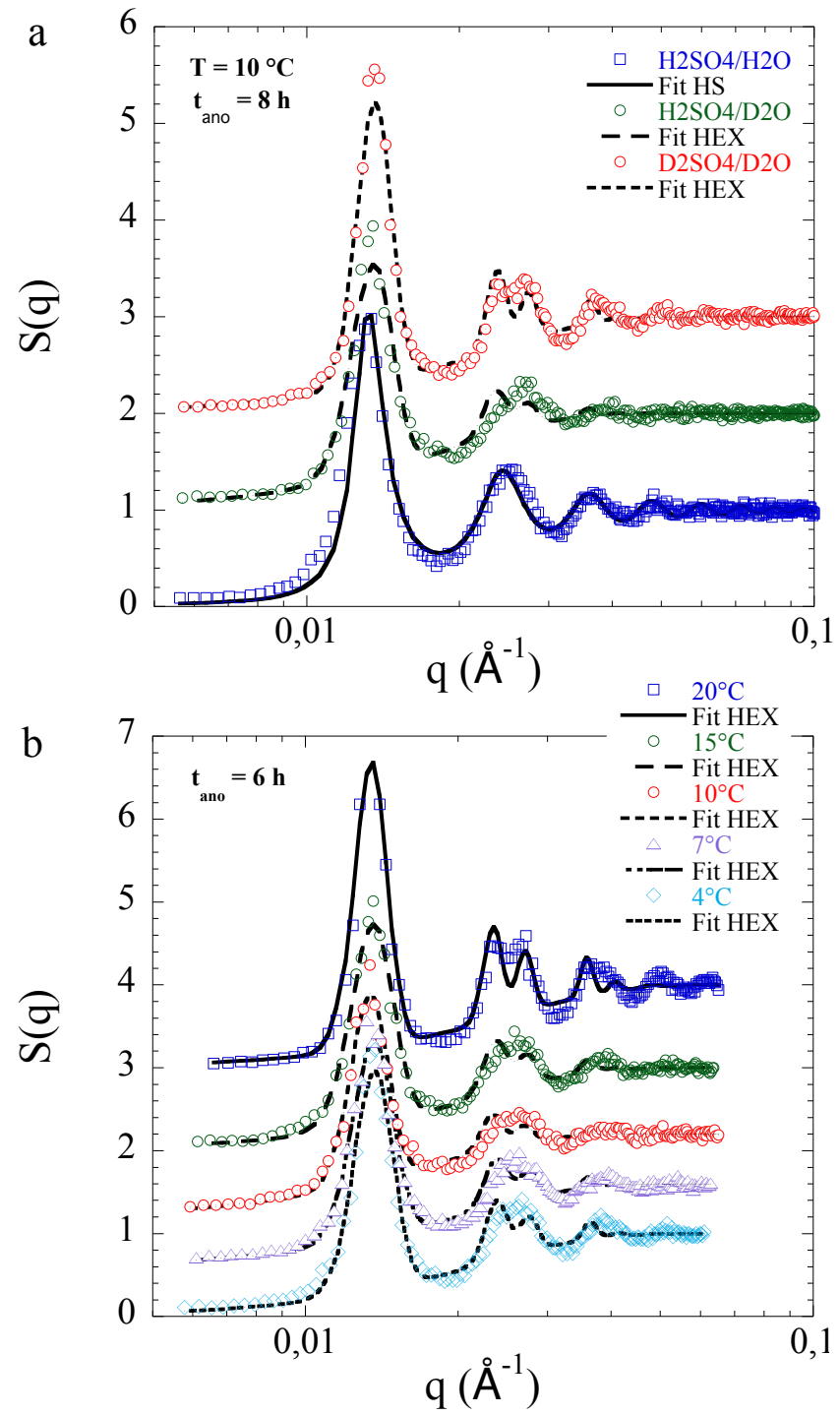

Figure 2: (a) Structure factor S(q) derived from the SEM images analysis fitted with hard sphere model in $\mathrm{H}_{2} \mathrm{SO}_{4} / \mathrm{H}_{2} \mathrm{O}$ and a hexagonal model for $\mathrm{H}_{2} \mathrm{SO}_{4} / \mathrm{D}_{2} \mathrm{O}$ and $\mathrm{D}_{2} \mathrm{SO}_{4} / \mathrm{D}_{2} \mathrm{O}$ (AAOs are synthesized during $8 \mathrm{~h}$ at $10{ }^{\circ} \mathrm{C}$ ). The curves have been shifted vertically for clarity. (b) Structure factor S(q) derived from the SEM images analysis of AAOs prepared in $\mathrm{D}_{2} \mathrm{SO}_{4} / \mathrm{D}_{2} \mathrm{O}$ at different temperatures with the corresponding hexagonal fits (anodization time of $6 \mathrm{~h}$ ). The SEM images are shown in Figure S2. 


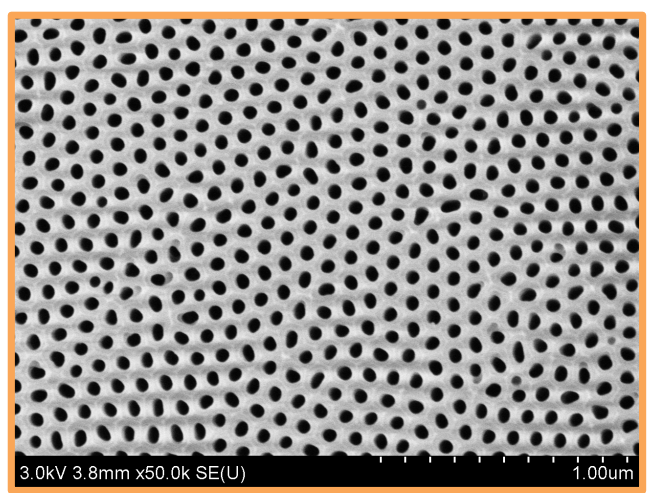

b
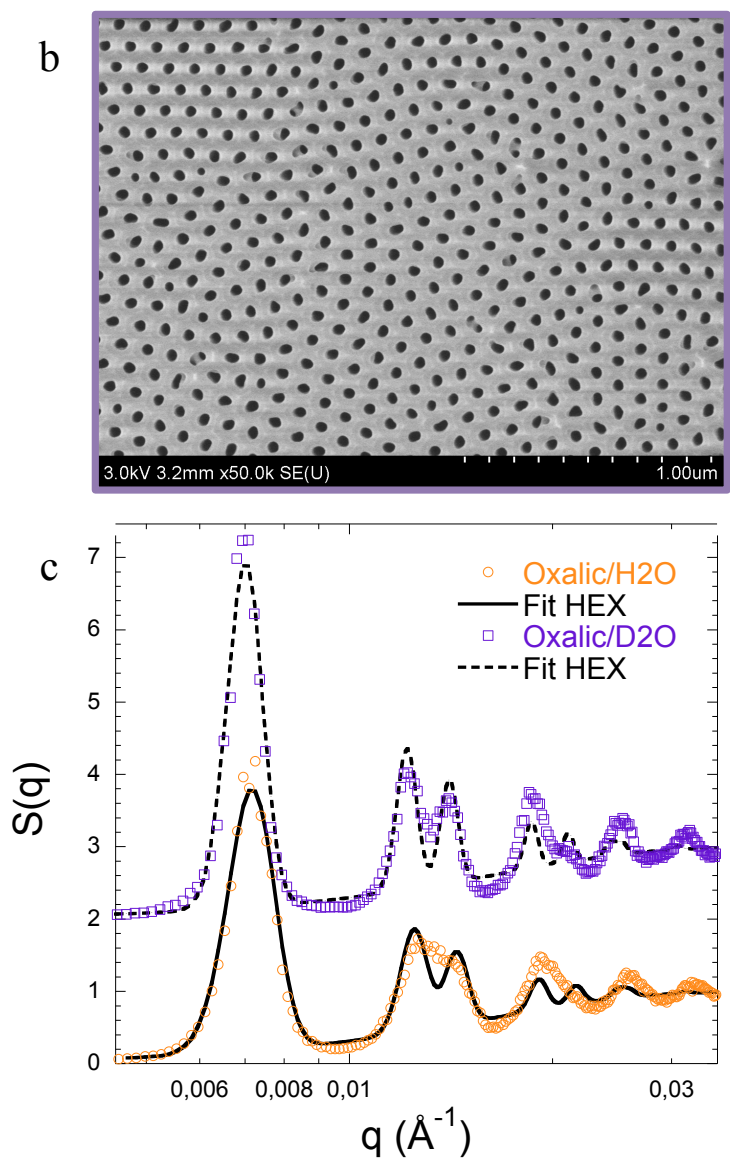

Figure 3: SEM images of AAOs synthesized with $\mathrm{OA}$ in (a) $\mathrm{H}_{2} \mathrm{O}$ and (b) $\mathrm{D}_{2} \mathrm{O}$. (c) S(q) derived from SEM analysis. The black lines correspond to the best hexagonal fits. The $\mathrm{S}(\mathrm{q})$ in $\mathrm{D}_{2} \mathrm{O}$ has been shifted for clarity. 
Table 2: Anion incorporation determined by EDS measurements.

\begin{tabular}{cccccc} 
Electrolytes & $\mathrm{H}_{2} \mathrm{SO}_{4} / \mathrm{H}_{2} \mathrm{O}$ & $\mathrm{H}_{2} \mathrm{SO}_{4} / \mathrm{D}_{2} \mathrm{O}$ & $\mathrm{D}_{2} \mathrm{SO}_{4} / \mathrm{D}_{2} \mathrm{O}$ & $\mathrm{OA} / \mathrm{H}_{2} \mathrm{O}$ & $\mathrm{OA} / \mathrm{D}_{2} \mathrm{O}$ \\
\hline $\mathrm{S} / \mathrm{Al}$ & $0.071+/-0.004$ & $0.091+/-0.005$ & $0.105+/-0.004$ & $\approx 0$ & $\approx 0$ \\
\hline $\mathrm{C} / \mathrm{Al}$ & $0.037+/-0.006$ & $0.036+/-0.005$ & $0.0245+/-0.0004$ & $0.100+/-0.008$ & $0.14+/-0.01$ \\
\hline Grain size $(\mathrm{nm})$ & $\mathrm{NA}$ & 314 & 370 & 714 & 997
\end{tabular}

the convergence of $\mathrm{U}_{B}$ to our working voltage.

Second, the increase in ordering can also be correlated to the incorporation of anions coming from the electrolyte during the anodization (sulfates or oxalates for sulfuric or oxalic acid respectively)[25]. Indeed, during the AAO growth, compressive stress arises at the oxide/electrolyte interface due to the incorporation of anions, which in turn produces tensile stress at the oxide/metal interface, causing the oxide plastic flow from the pore bottom to the pore surface[26] and finally influencing the pore self-ordering. Thus anion incorporation plays an important role: self-ordering increases when incorporation increases. In this context, we used Energy Dispersive Spectroscopy (EDS) to determine the incorporation level in AAOs, i.e. the $\mathrm{S} / \mathrm{Al}$ and $\mathrm{C} / \mathrm{Al}$ ratios for sulfuric and oxalic AAOs, respectively. To quantify the amount of $\mathrm{S}$ or $\mathrm{C}$ coming from external contamination (i.e. not from incorporation during the synthesis) we measure the $\mathrm{S}$ content of oxalic samples (where normally there is no $\mathrm{S}$ ) and the $\mathrm{C}$ content of sulfuric samples (where normally there is no $\mathrm{C}$ ). Table 2 shows the results. First, there is no $\mathrm{S}$ external contamination since none is measured in oxalic samples. However there is a $\mathrm{C}$ external contamination estimated around a $\mathrm{C} / \mathrm{Al}$ of 0.033 . Then a clear increase of $\mathrm{S} / \mathrm{Al}$ or $\mathrm{C} / \mathrm{Al}$ is observed when $\mathrm{D}_{2} \mathrm{O}$ is used as a solvent, indicating an increase of anion incorporations correlated with the increase in grain size. 


\subsubsection{Influence on the growth rate (GR)}

Now we will study the effect of $\mathrm{D}_{2} \mathrm{O}$ on the pore growth rate (GR, calculated from the AAO thickness obtained by cross section SEM images). In particular the GR can be explored through the current density $j$, modified here by changing the temperature or the voltage. Fig.4 shows the GR evolution with $j$ for sulfuric (Fig. 4a) and OA (Fig. 4b) electrolytes prepared in $\mathrm{H}_{2} \mathrm{O}$ and $\mathrm{D}_{2} \mathrm{O}$. For all electrolytes, the GR is linear with $j$ but different values of the slopes (given in Fig. 4a and 4b) are obtained depending on the solvent $\left(\mathrm{H}_{2} \mathrm{O}\right.$ or $\left.\mathrm{D}_{2} \mathrm{O}\right)$ or the nature of the electrolyte (sulfuric or OA). For sulfuric acid, the GR is larger in deuterated electrolytes (around $25 \%$ higher for $\left.\mathrm{D}_{2} \mathrm{SO}_{4} / \mathrm{D}_{2} \mathrm{O}\right)$, while there is no clear deuterated effect for oxalic electrolytes. To gain more understanding, the GR evolution can be discussed in relation with the activation energy $\mathrm{E}_{a}$ of the reaction process, i.e. aluminum oxidation during the first anodization. The $\mathrm{E}_{a}$ is obtained by fitting the $j$ versus $1 / \mathrm{T}$ plot (see Figure S3, the voltage is fixed to $20 \mathrm{~V}$ for sulfuric and $40 \mathrm{~V}$ for $\mathrm{OA}$ ) with the following Arrhenius equation:

$$
j=j_{0} \cdot \exp \left(-\frac{E_{a}}{R T}\right)
$$

For sulfuric electrolytes, one finds an $\mathrm{E}_{a}$ of $52+/-3,47+/-5$ and 41 $+/-3 \mathrm{~kJ} . \mathrm{mol}^{-1}$ for $\mathrm{H}_{2} \mathrm{SO}_{4} / \mathrm{H}_{2} \mathrm{O}, \mathrm{H}_{2} \mathrm{SO}_{4} / \mathrm{D}_{2} \mathrm{O}$ and $\mathrm{D}_{2} \mathrm{SO}_{4} / \mathrm{D}_{2} \mathrm{O}$, respectively. Thus an increase in GR can be correlated with a decrease in $\mathrm{E}_{a}$ when using $\mathrm{D}_{2} \mathrm{O}$ as a solvent. For $\mathrm{OA}$, the $\mathrm{E}_{a}$ remains quite similar between $\mathrm{H}_{2} \mathrm{O}$ and $\mathrm{D}_{2} \mathrm{O}$ : one gets an $\mathrm{E}_{a}$ of $46+/-3$ and $50+/-5 \mathrm{~kJ} \cdot \mathrm{mol}^{-1}$ for $\mathrm{OA} / \mathrm{H}_{2} \mathrm{O}$ and 

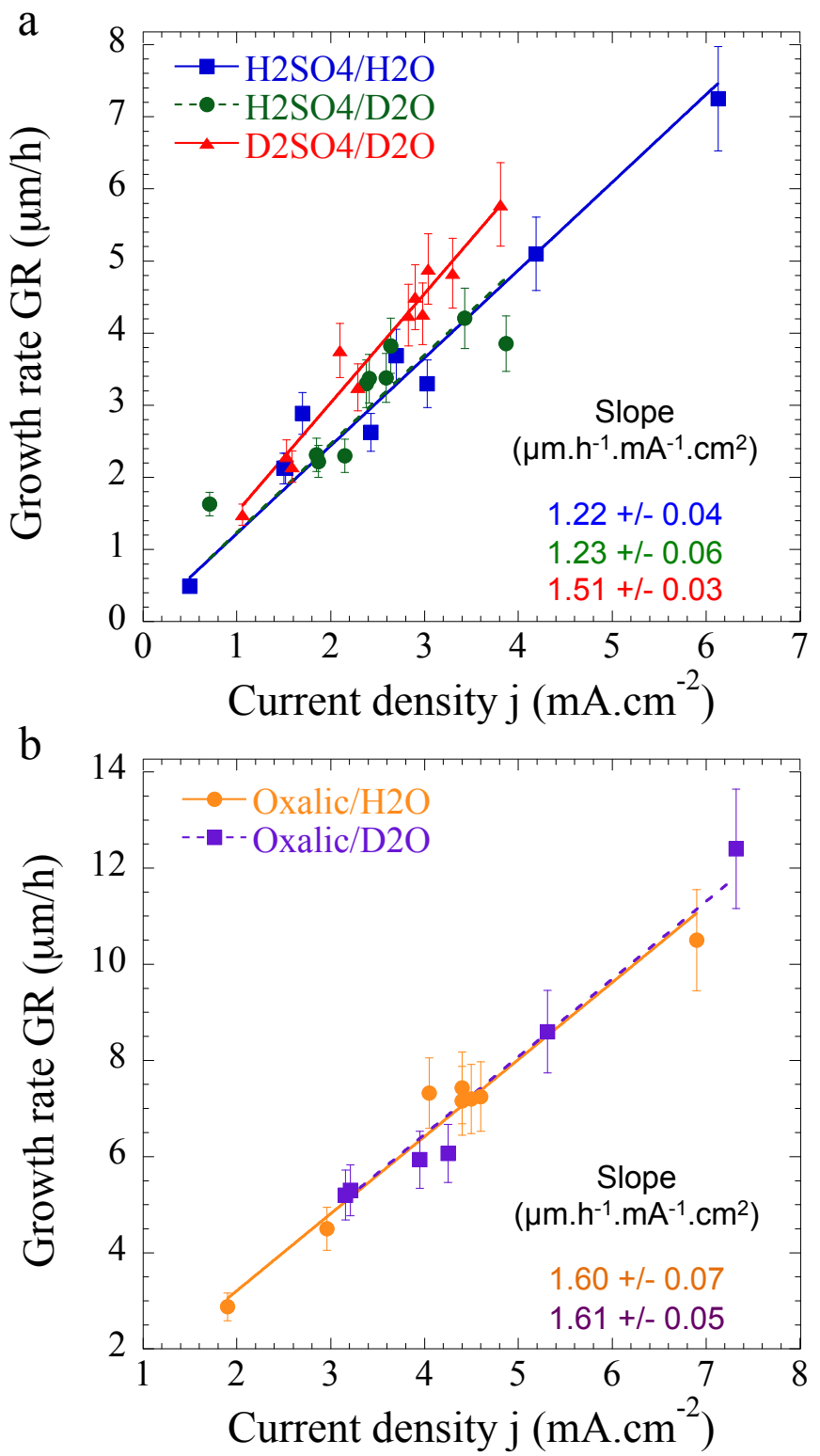

Figure 4: Growth rate (GR) as a function of the average current density j for (a) AAOs synthesized in $\mathrm{H}_{2} \mathrm{SO}_{4} / \mathrm{H}_{2} \mathrm{O}$ (blue squares), $\mathrm{H}_{2} \mathrm{SO}_{4} / \mathrm{D}_{2} \mathrm{O}$ (green circles) and $\mathrm{D}_{2} \mathrm{SO}_{4} / \mathrm{D}_{2} \mathrm{O}$ (red triangles) and (b) for AAOs synthesized in $\mathrm{OA} / \mathrm{H}_{2} \mathrm{O}$ (orange circles) and $\mathrm{OA} / \mathrm{D}_{2} \mathrm{O}$ (purple squares). 
$\mathrm{OA} / \mathrm{D}_{2} \mathrm{O}$, respectively, which is coherent with the similar GR values. It has to be noticed that for both electrolytes, the conductivity decreases in $\mathrm{D}_{2} \mathrm{O}$ (see Table S1), suggesting that the growth of AAOs in deuterated electrolyte is always more efficient.

From all the different structural aspects we presented, it is clear that deuterated electrolytes modify some important AAO structural features and can be thus an interesting alternative for the synthesis of AAOs with specific morphologies. It is known that the dissociation constants of acids are modified in $\mathrm{D}_{2} \mathrm{O}$ (because $\mathrm{D}_{2} \mathrm{O}$ has different physical properties such as a higher viscosity)[27]. Such differences have effects on the pore structure: for example, a lower acidity in $\mathrm{D}_{2} \mathrm{O}$ leads to smaller pore diameters (as low as the smallest values observed in the literature so far). However, other observations made in $\mathrm{D}_{2} \mathrm{O}$ cannot be fully understood: the increase of anion incorporation and the increase in GR for sulfuric suppose that $\mathrm{D}_{2} \mathrm{O}$ has a complex influence on the growth mechanism which is electrolyte dependent (here sulfuric and OA don't show the same effect on the GR). Alumina is obtained by the reaction of aluminium ions $\mathrm{Al}^{3+}$ coming from the $\mathrm{Al}$ oxidation with oxygen ions coming from water dissociation. The water dissociation rate under electric field, i.e. the rate for providing $\mathrm{O}^{2-}$ or $\mathrm{OH}^{-}$to form alumina, is a determining parameter that controls several processes in the AAO formation[28] such as the migration of anionic species within the material and a modification of such water dissociation in $\mathrm{D}_{2} \mathrm{O}$ might explain our results[29]. So far, no studies investigated such influence on AAOs but recent work reported clear electrochemical effects of isotopic substitution[30]. 


\subsection{Investigation of $O H$ incorporation and $A A O$ aging by $S A N S$}

\subsection{1. $O H$ incorporation in $A A O$}

The synthesis in deuterated electrolytes also allows to elucidate the presence of $\mathrm{H}$ within the AAOs due to the incorporation of $\mathrm{OH}^{-}$during the synthesis. The $\mathrm{OH}$ quantity can be determined by thermogravimetric measurements (TGA). Mata-Zamora et al.[31] investigated by TGA AAOs prepared in aqueous electrolytes of sulfuric, oxalic or phosphoric acid and proposed empirical chemical formulas having the following general expression: $\left(\mathrm{Al}_{2} \mathrm{O}_{3-x}\right)$ (anion) $)_{a}(\mathrm{OH})_{b}$ (anions being sulfates, oxalates or phosphates depending on the electrolyte nature). They found that AAOs prepared in sulfuric acid contained more $\mathrm{OH}$ and anions relative to the ones prepared in phosphoric or oxalic acid. However the total $\mathrm{OH}$ amount remains low $(b=$ 0.08, 0.04 and 0.001 for sulfuric, oxalic and phosphoric, respectively) indicating a weak $\mathrm{OH}$ incorporation. Then TGA cannot discriminate between surface $\mathrm{OH}$ and trapped $\mathrm{OH}$ inside the AAO. To solve this issue, O'Sullivan conducted FTIR measurements under $\mathrm{D}_{2} \mathrm{O}$ atmosphere and quantified the $\mathrm{H} / \mathrm{D}$ exchange. They observed that all $\mathrm{OH}$ groups are available for $\mathrm{H} / \mathrm{D}$ exchange suggesting that hydroxyl groups are located at the surface and not trapped inside the materials[32].

Here, the synthesis in $\mathrm{D}_{2} \mathrm{O}$ can provide further information about the $\mathrm{OH}$ incorporation. Indeed, such presence in the structure can be revealed by substituting $\mathrm{D}$ for $\mathrm{H}$ during the synthesis by the use of $\mathrm{D}_{2} \mathrm{O}$ and then performing Small-Angle Neutron Scattering (SANS). SANS is a technique very sensitive to deuteration since atoms $\mathrm{H}$ and $\mathrm{D}$ have very different neutron scattering length $b\left(\mathrm{~b}_{H}=-0.374 \times 10^{-12} \mathrm{~cm}\right.$ and $\left.\mathrm{b}_{D}=0.667 \times 10^{-12} \mathrm{~cm}\right)$. As 
mentioned in the experimental section, the chemical composition is given in SANS by the scattering length density (SLD, noted $\rho$ ) values, which are obtained by the fitting of the SANS data[21] and depend on the chemical formula and the density of the material as follows:

$$
\rho=\frac{d N_{a}}{M} \sum_{i} b_{i}
$$

With $\mathrm{d}$ the density, $\mathrm{N}_{a}$ the Avogadro number, $\mathrm{M}$ the molecular weight and $b_{i}$ the scattering length of atom $i$. Thus, a difference in SLD can be explained by a difference in composition or by a difference in the density of the materials. As a consequence, the comparison of the SLD values of hydrogenated and deuterated AAOs will reveal the $\mathrm{OH}$ incorporation of alumina: if $\mathrm{AAO}$ contains $\mathrm{OH}$ groups then the differences between AAOs synthesized in $\mathrm{H}_{2} \mathrm{O}$ or $\mathrm{D}_{2} \mathrm{O}$ will be observed. On the contrary, if there is no $\mathrm{H}$ (or if the $\mathrm{H}$ quantity is too low to be detected) then the SLDs will be similar. The sensitivity can be evaluated by estimating the expected SLD values. With the empirical formulas proposed by Mata-Zamora[31] one can calculate the AAO SLD and, by substituting $\mathrm{D}$ for $\mathrm{H}$ and assuming a similar density (3 g.cm ${ }^{-3}$ ), the expected SLD for AAO synthesized in deuterated electrolytes. One finds $4.24 \times 10^{-6} \AA^{-2}$ and $4.36 \times 10^{-6} \AA^{-2}$ for AAOs synthesized in $\mathrm{H}_{2} \mathrm{O}$ and $\mathrm{D}_{2} \mathrm{O}$, respectively. The difference (around $3 \%$ ) is detectable by SANS due to the high AAO scattering, the error bars of the SLD values extracted from the data fitting lie on the second digits[21] .

Figure $5 \mathrm{a}$ and $5 \mathrm{~b}$ shows the scattering intensities of AAOs synthesized in $\mathrm{H}_{2} \mathrm{SO}_{4} / \mathrm{H}_{2} \mathrm{O}$ (blue circles) and $\mathrm{D}_{2} \mathrm{SO}_{4} / \mathrm{D}_{2} \mathrm{O}$ (red squares) measured in 73.2 $\%$ and $75.5 \% \mathrm{D}_{2} \mathrm{O}$, respectively. As explained in the experimental sec- 

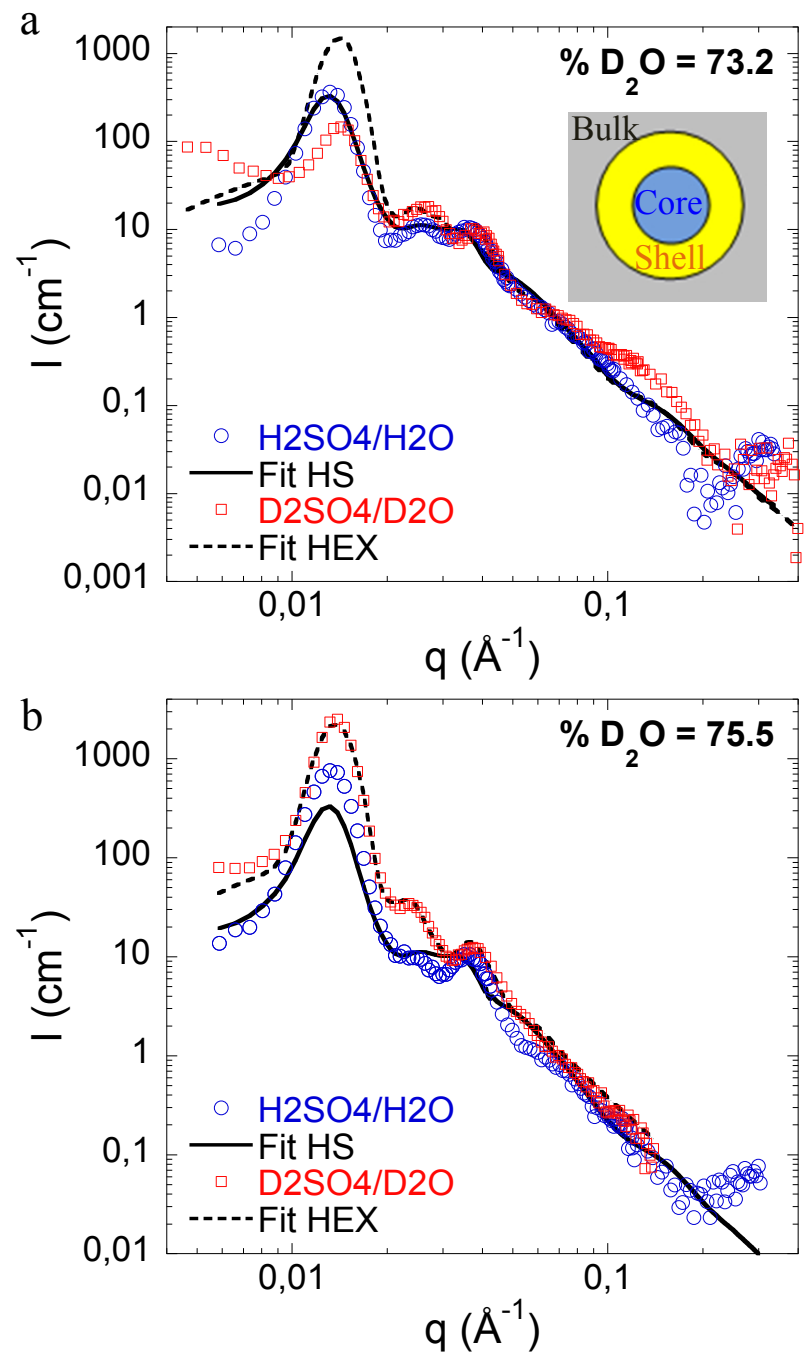

Figure 5: (a) SANS scattering intensities of AAOs synthesized in $\mathrm{H}_{2} \mathrm{SO}_{4} / \mathrm{H}_{2} \mathrm{O}$ (blue circles) and $\mathrm{D}_{2} \mathrm{SO}_{4} / \mathrm{D}_{2} \mathrm{O}$ (red squares) measured in (a) $73.2 \%$ and (b) $75.5 \% \mathrm{D}_{2} \mathrm{O}$. The continuous and dashed lines correspond to the best fit. The scheme inserted in (a) represents the core/shell model used to fit the data. 
tion, the data have been fitted with a model combining an aligned core/shell cylinder form factor (depicted in insert of Fig. 5a) and a hard sphere or hexagonal structure factor. All the details of this model are fully described in our previous work[21] and Table 3 lists all the fitting parameters. This model nicely reproduced the experimental data (except for the first peak of the $\mathrm{D}_{2} \mathrm{SO}_{4} / \mathrm{D}_{2} \mathrm{O}$ AAOs in $73.2 \% \mathrm{D}_{2} \mathrm{O}$, this discrepancy being attributed to possible micro cracks adding a Porod contribution at low q and different information can be extracted:

i) SANS measurements confirms the better ordering of the $\mathrm{D}_{2} \mathrm{SO}_{4} / \mathrm{D}_{2} \mathrm{O}$ AAOs: the longitudinal correlation length $\mathrm{L}_{z}$, corresponding to an ordering length in the longitudinal direction, is larger for $\mathrm{D}_{2} \mathrm{SO}_{4} / \mathrm{D}_{2} \mathrm{O}(4.43 \mu \mathrm{m})$ than the $\mathrm{H}_{2} \mathrm{SO}_{4} / \mathrm{H}_{2} \mathrm{O}(1.74 \mu \mathrm{m})$.

ii) as for AAOs prepared in OA[21], the AAOs made in sulfuric acid are not homogenous in composition, the SANS cannot be fitted without a contaminated shell of $5.2 \mathrm{~nm}$ and $6.3 \mathrm{~nm}$ for $\mathrm{H}_{2} \mathrm{SO}_{4} / \mathrm{H}_{2} \mathrm{O}$ and $\mathrm{D}_{2} \mathrm{SO}_{4} / \mathrm{D}_{2} \mathrm{O}$, respectively. The composition of the shell will be discussed with the SLD below.

iii) since the same structural parameters have been used for the fitting of the $73.2 \%$ and $75.5 \% \mathrm{D}_{2} \mathrm{O}$, more reliable SLD values are obtained by averaging the shell and bulk SLD determined for both contrasts. The SLDs gives information about the AAOs chemical composition and its possible hydration. One obtains $\rho_{\text {shell }}=(4.61+/-0.09) \times 10^{-6} \AA^{-2}$ and $\rho_{\text {bulk }}=(4.49$ $+/-0.09) \times 10^{-6} \AA^{-2}$ for $\mathrm{H}_{2} \mathrm{SO}_{4} / \mathrm{H}_{2} \mathrm{O}$ and $\rho_{\text {shell }}=(4.59+/-0.08) \times 10^{-6} \AA^{-2}$ and $\rho_{\text {bulk }}=(4.50+/-0.07) \times 10^{-6} \AA^{-2}$ for $\mathrm{D}_{2} \mathrm{SO}_{4} / \mathrm{D}_{2} \mathrm{O}$. The $\rho_{\text {shell }}$ is higher than $\rho_{\text {bulk }}$ suggesting the incorporation in the shell of elements increasing the 


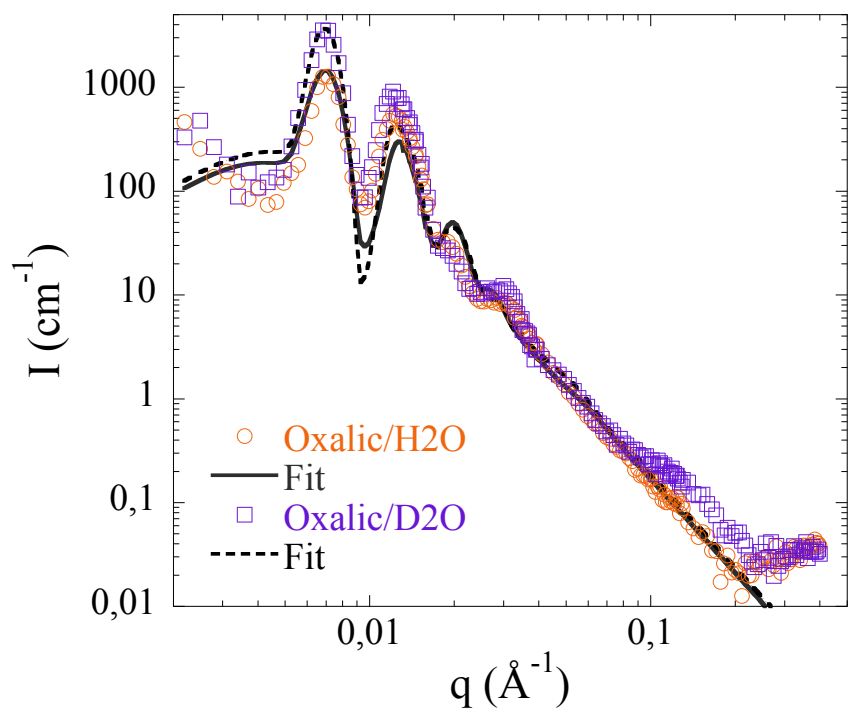

Figure 6: SANS scattering intensities of AAOs synthesized in $\mathrm{OA} / \mathrm{H}_{2} \mathrm{O}$ (orange circles) and $\mathrm{OA} / \mathrm{D}_{2} \mathrm{O}$ (purple squares). The continuous and dashed lines correspond to the best fit.

SLD (such as S), in good agreement with the previous EDS characterization. However, no differences in SLD are observed when comparing deuterated and hydrogenated electrolytes. As mentioned previously, the SLDs depend on a combined effect of density and chemical composition. In $\mathrm{D}_{2} \mathrm{O}$, an increase in anion incorporation (increasing the SLD) is accompanied with a decrease in density (decreasing the SLD), leading to comparable SLD values as in $\mathrm{H}_{2} \mathrm{O}$. In addition, our results suggest that the $\mathrm{OH}$ or $\mathrm{OD}$ incorporation during the synthesis is very weak and not detected by SANS.

Similarly, SANS of AAOs synthesized in OA doesn't show drastic differences between $\mathrm{H}_{2} \mathrm{O}$ and $\mathrm{D}_{2} \mathrm{O}$ as seen in Figure 6 where the SANS data superimpose; the small differences are due to the better ordering in $\mathrm{D}_{2} \mathrm{O}$ (see fitting parameters in Table 3). The SLD values obtained by the fit are 
Table 3: Parameters obtained by the fitting of SANS data in Figure 4. See reference[21] for full details. The ${ }^{*}$ refers to fixed parameters during the SANS fitting. ${ }^{a}$ For $\mathrm{H}_{2} \mathrm{SO}_{4} / \mathrm{H}_{2} \mathrm{O}$, a HS model has been used for the $\mathrm{S}(\mathrm{q})$.

\begin{tabular}{cccccccc} 
Name & $\mathrm{H}_{2} \mathrm{SO}_{4} / \mathrm{H}_{2} \mathrm{O}^{a}$ & $\mathrm{H}_{2} \mathrm{SO}_{4} / \mathrm{H}_{2} \mathrm{O}^{a}$ & $\mathrm{D}_{2} \mathrm{SO}_{4} / \mathrm{D}_{2} \mathrm{O}$ & $\mathrm{D}_{2} \mathrm{SO}_{4} / \mathrm{D}_{2} \mathrm{O}$ & $\mathrm{OA} / \mathrm{H}_{2} \mathrm{O}$ & $\mathrm{OA} / \mathrm{D}_{2} \mathrm{O}$ & $\mathrm{F}(\mathrm{q})$ or $\mathrm{S}(\mathrm{q})$ \\
\hline$\% \mathrm{D}_{2} \mathrm{O}$ & 75.5 & 73.2 & 75.5 & 73.2 & 73.2 & 73.2 & - \\
\hline $\mathrm{D}_{\text {int }}(\mathrm{nm})$ & 52.6 & 52.6 & 51.5 & 50 & 97.5 & 102 & $\mathrm{~S}(\mathrm{q})$ \\
\hline$\sigma_{a}$ & - & - & 0.084 & 0.084 & 0.061 & 0.058 & $\mathrm{~S}(\mathrm{q})$ \\
\hline$\delta\left(\mathrm{x} 10^{-4} \AA^{-1}\right)$ & 0.49 & 0.49 & 17 & 17 & 8.8 & 6 & $\mathrm{~S}(\mathrm{q})$ \\
\hline $\mathrm{c}_{L}$ & - & - & 24.2 & 30 & 12 & 13 & $\mathrm{~S}(\mathrm{q})$ \\
\hline$* \phi_{s}$ & 0.35 & 0.35 & 0.27 & 0.27 & 0.62 & 0.58 & $\mathrm{~F}(\mathrm{q})$ \\
\hline$* \rho_{\text {solv }}\left(10^{-6} \AA^{-2}\right)$ & 4.65 & 4.52 & 4.65 & 4.52 & 4.52 & 4.52 & $\mathrm{~F}(\mathrm{q})$ \\
\hline$\rho_{\text {shell }}\left(10^{-6} \AA^{-2}\right)$ & 4.68 & 4.55 & 4.65 & 4.54 & 4.54 & 4.53 & $\mathrm{~F}(\mathrm{q})$ \\
\hline$\rho_{\text {bulk }}\left(10^{-6} \AA^{-2}\right)$ & 4.55 & 4.42 & 4.55 & 4.45 & 4.43 & 4.45 & $\mathrm{~F}(\mathrm{q})$ \\
\hline$* \mathrm{R}_{p}(\mathrm{~nm})$ & 10 & 10 & 8 & 8 & 27.5 & 23.5 & $\mathrm{~F}(\mathrm{q})$ \\
\hline$\sigma_{p}$ & 0.2 & 0.2 & 0.19 & 0.19 & 0.06 & 0.07 & $\mathrm{~F}(\mathrm{q})$ \\
\hline $\mathrm{t}(\mathrm{nm})$ & 5.8 & 5.7 & 6.3 & 6.3 & 15 & 17.5 & $\mathrm{~F}(\mathrm{q})$ \\
\hline$* \sigma_{t}$ & 0.1 & 0.1 & 0.1 & 0.1 & 0.2 & 0.1 & $\mathrm{~F}(\mathrm{q})$ \\
\hline$* \mathrm{~L}_{z}(\mu \mathrm{m})$ & 1.74 & 1.74 & 4.43 & 4.43 & 2.28 & 3.62 & $\mathrm{~F}(\mathrm{q})$
\end{tabular}

similar for $\mathrm{H}_{2} \mathrm{O}$ and $\mathrm{D}_{2} \mathrm{O}$ suggesting again an absence or a weak $\mathrm{OH}$ or OD incorporation, also confirmed by similar FTIR measurements (see Figure S4). Our results are consistent with the observations of O'Sullivan et al.[32] who concluded that no $\mathrm{OH}$ are trapped in the materials but are at the surface. One can imagine that surface OD groups are present after the synthesis in deuterated electrolytes and that further $\mathrm{H} / \mathrm{D}$ exchange occurs with the $\mathrm{H}_{2} \mathrm{O}$ molecules of the solvent mixture used for SANS measurements.

\subsection{2. $\mathrm{AAO}$ aging in $\mathrm{H}_{2} \mathrm{O}$ and $\mathrm{D}_{2} \mathrm{O}$}

Finally, we propose to follow the AAO aging after a long immersion in $\mathrm{H}_{2} \mathrm{O}$ or $\mathrm{D}_{2} \mathrm{O}$ at room temperature. It has been observed that, in water, 
alumina transforms into aluminum hydroxydes boehmite $(\mathrm{AlOOH})$ or more probably bayerite $\left(\mathrm{Al}(\mathrm{OH})_{3}\right)$, such transformation being thermodynamically favored but kinetically slow[33]. Such process induces at the AAO surface a pore sealing, an interesting property for applications involving corrosion resistance. Here, we aim in particular at studying the effect of $\mathrm{D}_{2} \mathrm{O}$ on this sealing process.

Pieces of AAO synthesized in $\mathrm{OA} / \mathrm{H}_{2} \mathrm{O}$ are immersed in $\mathrm{H}_{2} \mathrm{O}$ or $\mathrm{D}_{2} \mathrm{O}$ during 30 days at room temperature. These samples are then measured by SANS in $73.2 \% \mathrm{D}_{2} \mathrm{O}$ mixture. Figure 7a shows the SANS spectra after immersing the AAO 30 days in $\mathrm{H}_{2} \mathrm{O}$ (green squares) or $\mathrm{D}_{2} \mathrm{O}$ (red circles). For comparison we also plotted the SANS signal of the "as prepared" sample, i.e. AAO that has not been immersed[21]. First, compared to the as prepared $\mathrm{AAO}$, the whole scattering intensities of "immersed" AAOs are shifted vertically after the immersion both in $\mathrm{H}_{2} \mathrm{O}$ or $\mathrm{D}_{2} \mathrm{O}$. Second, the amplitudes of the different peaks at low q are also modified with an increase of the first peak more pronounced after immersion in $\mathrm{H}_{2} \mathrm{O}$ than in $\mathrm{D}_{2} \mathrm{O}$ and high incoherent plateaus are clearly visible at high q with similar levels for AAOs immersed in $\mathrm{H}_{2} \mathrm{O}$ and $\mathrm{D}_{2} \mathrm{O}$. All these modifications in the SANS curves indicates changes in the AAO composition. Further data fitting also shown in Figure 7a provides the results presented in Table 4. One can notice that the pore hexagonal organization and radius are barely affected by the aging but the shell and bulk SLD values decrease in both cases, this decrease being more pronounced after immersion in $\mathrm{H}_{2} \mathrm{O}$. In the case of $\mathrm{AAO}$ immersed in $\mathrm{H}_{2} \mathrm{O}$, such SLD decrease is consistent with the alumina transformation into aluminum hydroxyde (bayerite), i.e. with the presence of $\mathrm{H}$ in the material. 

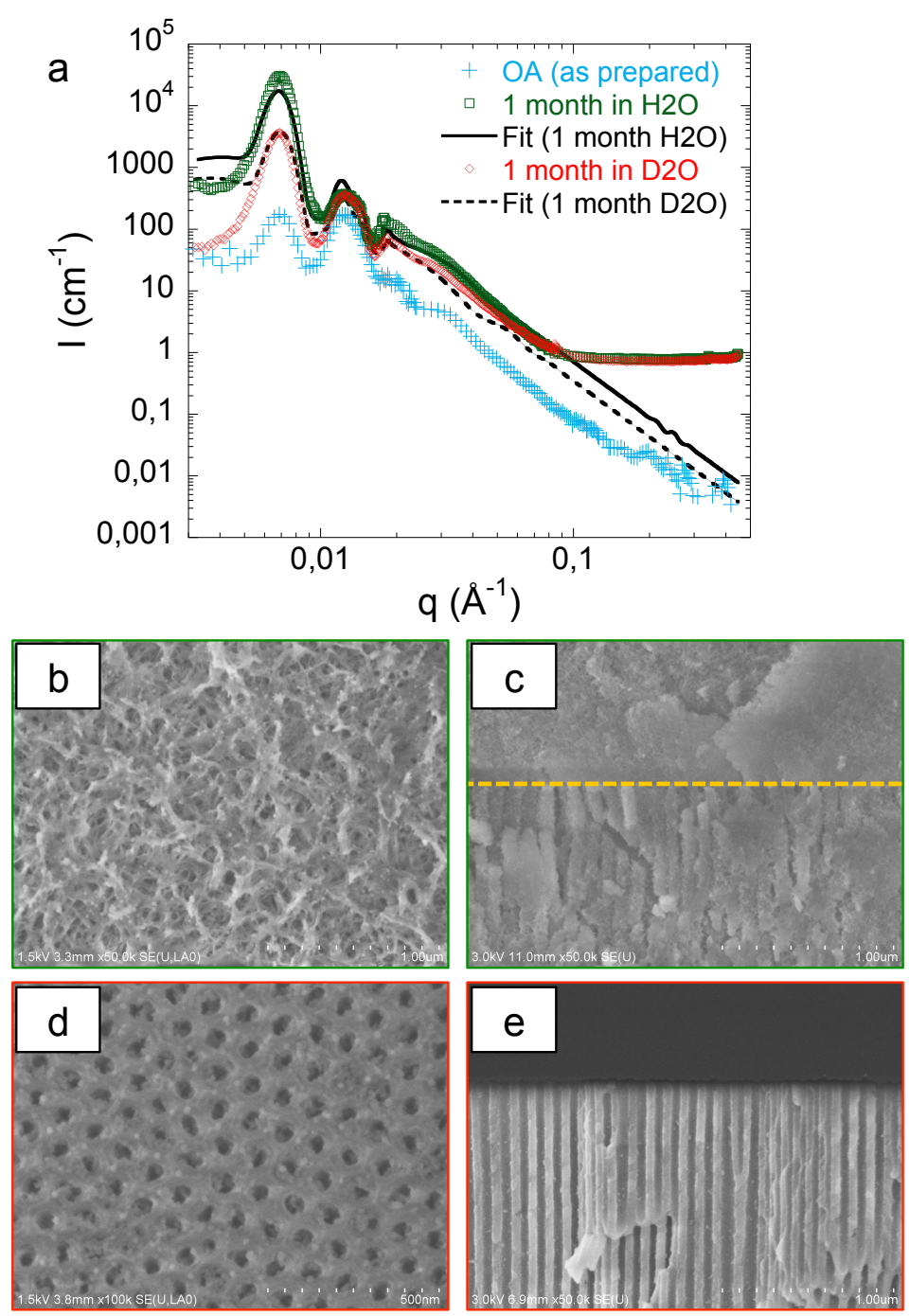

Figure 7: (a) SANS scattering intensities of AAOs synthesized in $\mathrm{OA} / \mathrm{H}_{2} \mathrm{O}$ measured in $73.2 \mathrm{D}_{2} \mathrm{O}$ as prepared (blue crosses), after immersion in $\mathrm{H}_{2} \mathrm{O}$ (green squares) and $\mathrm{D}_{2} \mathrm{O}$ (red circles). The continuous and dashed lines correspond to the best fit. The as prepared AAO has already been fitted in our previous work[21].(b, c, d, e) Top and section SEM images of $\mathrm{AAO}$ synthesized in $\mathrm{OA} / \mathrm{H}_{2} \mathrm{O}$ after 30 days immersion in $\mathrm{H}_{2} \mathrm{O}(\mathrm{b}, \mathrm{c})$ or $\mathrm{D}_{2} \mathrm{O}(\mathrm{d}$, e). 
Table 4: Parameters obtained by the fitting of SANS data in Figure 7. See reference[21] for full details. The ${ }^{*}$ refers to fixed parameters during the SANS fitting. These samples were measured in $73.2 \% \mathrm{D}_{2} \mathrm{O}$ mixture. The as prepared AAO has already been fitted in our previous work.[21].

\begin{tabular}{cccc} 
Name & As prepared & 1 month in $\mathrm{H}_{2} \mathrm{O}$ & 1 month in $\mathrm{D}_{2} \mathrm{O}$ \\
\hline $\mathrm{D}_{\text {int }}(\mathrm{nm})$ & 100 & 103 & 101 \\
\hline$\sigma_{a}$ & 0.06 & 0.06 & 0.06 \\
\hline$\delta\left(\mathrm{x} 10^{-4} \AA^{-1}\right)$ & 9.5 & 7 & 7 \\
\hline $\mathrm{c}_{L}$ & 10 & 10 & 10 \\
\hline$* \phi_{s}$ & 0.56 & 0.67 & 0.79 \\
\hline$* \rho_{\text {solv }}\left(10^{-6} \AA^{-2}\right)$ & 4.52 & 4.52 & 4.52 \\
\hline$\rho_{\text {shell }}\left(10^{-6} \AA^{-2}\right)$ & 4.58 & 4.40 & 4.48 \\
\hline$\rho_{\text {bulk }}\left(10^{-6} \AA^{-2}\right)$ & 4.50 & 4.12 & 4.28 \\
\hline$* \mathrm{R}_{p}(\mathrm{~nm})$ & 26.7 & 26.7 & 26.7 \\
\hline$\sigma_{p}$ & 0.14 & 0.25 & 0.25 \\
\hline $\mathrm{t}(\mathrm{nm})$ & 15 & 19 & 23 \\
\hline$\sigma_{t}$ & 0.1 & 0.2 & 0.1 \\
\hline$* \mathrm{~L}_{z}(\mu \mathrm{m})$ & 1.33 & 1.33 & 1.33
\end{tabular}

In the case $\mathrm{AAO}$ immersed in $\mathrm{D}_{2} \mathrm{O}$, one can propose the same transformation with the presence of $\mathrm{D}$ in the AAO. However, deuterium should increase the SLD values while a SLD decrease is measured, suggesting $\mathrm{H} / \mathrm{D}$ exchange during the SANS measurement.

To go further we performed SEM to confirm the SANS analysis. Figures $7 \mathrm{~b}, \mathrm{c}, \mathrm{d}$, e show top and section view of AAO immersed in $\mathrm{H}_{2} \mathrm{O}$ (b, c) and $\mathrm{D}_{2} \mathrm{O}(\mathrm{d}, \mathrm{e})$. For $\mathrm{AAO}$ immersed in $\mathrm{H}_{2} \mathrm{O}$ the pores are not anymore 
visible on the top surface (Fig. 7b), confirming the alumina transformation and pore sealing. However this sealing only affects the top surface, as seen on the SEM section view (Fig. 7c) where nanochannels are still present below a non-porous layer. On the contrary, for AAO immersed in $\mathrm{D}_{2} \mathrm{O}$, there is no non-porous layer on the top surface (Fig. $7 \mathrm{~d}$, e), the pores are still visible. O'Sullivan et al. speculated that hydrothermal AAO treatment doesn't modify the AAO bulk composition but induces a pore sealing[32]. Here, we show by combining SANS and SEM that aging in water affects the AAO composition, even before the pore sealing (see aging in $\mathrm{D}_{2} \mathrm{O}$ where no sealing is observed but SLDs values changed). Additionally, our results clearly evidence a much slower kinetic of alumina transformation in $\mathrm{D}_{2} \mathrm{O}$.

\section{Conclusion}

In this paper we proposed an experimental alternative to synthesize AAOs with interesting structural features by using deuterated electrolytes. The use of $\mathrm{D}_{2} \mathrm{O}$ leads to the formation of smaller pores with an improved hexagonal ordering. The pore diameter reached with deuterated electrolytes is as small as the smallest pore size obtained so far in the literature. Moreover, for sulfuric electrolytes, an increase in GR is observed and related to a decrease of the activation energy of aluminum oxidation. Additionally, deuterated electrolytes allow to quantify the possible $\mathrm{OH}$ incorporation in AAOs during the synthesis by the use of SANS. SANS measurements don't show drastic changes between hydrogenated and deuterated AAOs suggesting a weak $\mathrm{OH}$ incorporation. Finally, the $\mathrm{AAO}$ aging in $\mathrm{H}_{2} \mathrm{O}$ or $\mathrm{D}_{2} \mathrm{O}$ has also been inves-

tigated and our results shows that the alumina transformation is kinetically 
slower in $\mathrm{D}_{2} \mathrm{O}$. This work provides an efficient opportunities to synthesize AAOs with specific morphologies and brings new fundamental insight into the effect of deuterated species in the synthesis and properties of nanoporous materials.

\section{Acknowledgements}

The authors thank the Institut des Matériaux de Paris Centre (IMPC FR2482) for servicing FEGSEM and EDX instrumentation and Sorbonne Université, CNRS and C'Nano projects of the Région Ile-de-France for his funding and we thank David Montero for his help during the SEM characterization. We also thank Lionel Porcar for his help during the SANS experiments on D11 at ILL. Laboratoire Léon Brillouin (LLB) and Institut Laue Langevin (ILL) are acknowledged for beamtime allocation.

\section{References}

[1] P. Huber, Soft matter in hard confinement: phase transition thermodynamics, structure, texture, diffusion and flow in nanoporous media, Journal of Physics-Condensed Matter 27 (10) (2015) 103102.

[2] F. Tian, J. Lyu, J. Shi, F. Tan, M. Yang, A polymeric microfluidic device integrated with nanoporous alumina membranes for simultaneous detection of multiple foodborne pathogens, Sensors and Actuators B: Chemical 225 (2016) 312-318.

[3] C. T. Sousa, D. C. Leitao, M. P. Proenca, J. Ventura, A. M. Pereira, J. P. Araujo, Nanoporous alumina as templates for multifunctional applications, Applied Physics Reviews 1 (3) (2014) 031102. 
[4] H. Masuda, K. Fukuda, Ordered metal nanohole arrays made by a twostep replication of honeycomb structures of anodic alumina, Science 268 (1995) 1466-1468.

[5] W. Lee, R. Ji, U. Gosele, K. Nielsch, Fast fabrication of long-range ordered porous alumina membranes by hard anodization, Nat Mater 5 (9) (2006) 741-747, 10.1038/nmat1717.

[6] W. Lee, S. J. Park, Porous anodic aluminum oxide: Anodization and templated synthesis of functional nanostructures, Chemical Reviews 114 (15) (2014) 7487-7556.

[7] S. Ono, M. Saito, H. Asoh, Self-ordering of anodic porous alumina formed in organic acid electrolytes, Electrochimica Acta 51 (5) (2005) 827-833.

[8] O. Nishinaga, T. Kikuchi, S. Natsui, R. O. Suzuki, Rapid fabrication of self-ordered porous alumina with 10-/sub-10-nm-scale nanostructures by selenic acid anodizing, Scientific Reports 3 (2013) 2748.

[9] J. Martin, C. V. Manzano, O. Caballero-Calero, M. Martin-Gonzalez, High-aspect-ratio and highly ordered 15-nm porous alumina templates, Acs Applied Materials and Interfaces 5 (1) (2013) 72-79.

[10] C. Cheng, K. Ng, A. Ngan, Quantitative characterization of acid concentration and temperature dependent self-ordering conditions of anodic porous alumina, AIP Advances 1 (4) (2011) 042113.

[11] W. Chen, J.-S. Wu, X.-H. Xia, Porous anodic alumina with continuously manipulated pore/cell size, ACS Nano 2 (5) (2008) 959-965. 
[12] W. J. Stepniowski, D. Forbot, M. Norek, M. Michalska-Domanska, A. Król, The impact of viscosity of the electrolyte on the formation of nanoporous anodic aluminum oxide, Electrochimica Acta 133 (2014) $57-64$.

[13] X. Qin, J. Zhang, X. Meng, L. Wang, C. Deng, G. Ding, H. Zeng, X. Xu, Effect of ethanol on the fabrication of porous anodic alumina in sulfuric acid, Surface and Coatings Technology 254 (2014) 398-401.

[14] M. Salerno, N. Patra, R. Losso, R. Cingolani, Increased growth rate of anodic porous alumina by use of ionic liquid as electrolyte additive, Materials Letters 63 (21) (2009) 1826-1829.

[15] G. Dorsey, The characterization of anodic aluminas iii. barrier layer composition and structure, Journal of The Electrochemical Society 113 (3) (1966) 284-286.

[16] P. H. D. Lu, H. Strutzberg, S. Wenham, A. Lennon, Hydrogen incorporation during aluminium anodisation on silicon wafer surfaces, Electrochimica Acta 133 (2014) 153-160.

[17] T. P. Hoar, N. F. Mott, A mechanism for the formation of porous anodic oxide films on aluminium, Journal of Physics and Chemistry of Solids 9 (2) (1959) 97-99.

[18] I. Farnan, R. Dupree, A. J. Forty, Y. S. Jeong, G. E. Thompson, G. C. Wood, Structural information about amorphous anodic alumina from 27al mas nmr, Philosophical Magazine Letters 59 (4) (1989) 189-195. 
[19] N. Jouault, A. Chennevière, A. Christoulaki, E. Dubois, L. Porcar, Polyelectrolytes chain conformation under confinement: electrostatic effects studied by zero average contrast method. institut laue-langevin (ill), https://doi.org/10.5291/ill-data.9-11-1764 (2016).

[20] C. D. Dewhurst, $\quad$ Graphical reduction and analysis sans program for matlabtm, https://www.ill.eu/users/scientific-groups/large-scale-structures/grasp/.

[21] A. Christoulaki, A. Chenneviere, I. Grillo, L. Porcar, E. Dubois, N. Jouault, A novel methodology to study nanoporous alumina by smallangle neutron scattering, Journal of Applied Crystallography 52 (4) (2019) 745-754.

[22] S. Förster, A. Timmann, M. Konrad, C. Schellbach, A. Meyer, S. S. Funari, P. Mulvaney, R. Knott, Scattering curves of ordered mesoscopic materials, The Journal of Physical Chemistry B 109 (4) (2005) 13471360.

[23] S. J. Hurst, E. K. Payne, L. Qin, C. A. Mirkin, Multisegmented onedimensional nanorods prepared by hard-template synthetic methods, Angewandte Chemie International Edition 45 (17) (2006) 2672-2692.

[24] S. Chu, K. Wada, S. Inoue, M. Isogai, A. Yasumori, Fabrication of ideally ordered nanoporous alumina films and integrated alumina nanotubule arrays by high?field anodization, Advanced Materials 17 (17) (2005) $2115-2119$. 
[25] I. Mínguez-Bacho, S. Rodríguez-López, A. Climent, D. Fichou, M. Vázquez, M. Hernández-Vélez, Influence of sulfur incorporation into nanoporous anodic alumina on the volume expansion and self-ordering degree, The Journal of Physical Chemistry C 119 (49) (2015) 2739227400 .

[26] J. E. Houser, K. R. Hebert, The role of viscous flow of oxide in the growth of self-ordered porous anodic alumina films, Nat Mater 8 (5) (2009) 415-420, 10.1038/nmat2423.

[27] W. P. Jencks, K. Salvesen, Equilibrium deuterium isotope effects on the ionization of thiol acids, Journal of the American Chemical Society 93 (18) (1971) 4433-4436.

[28] Z. Su, M. Bühl, W. Zhou, Dissociation of water during formation of anodic aluminum oxide, Journal of the American Chemical Society 131 (24) (2009) 8697-8702.

[29] J. J. Katz, Chemical and biological studies with deuterium, American Scientist 48 (4) (1960) 544-580.

[30] S. Cai, T. Bai, H. Chen, W. Fang, Z. Xu, H. Lai, T. Huang, H. Xu, X. Chu, J. Ling, C. Gao, Heavy water enables high-voltage aqueous electrochemistry via the deuterium isotope effect, The Journal of Physical Chemistry Letters 11 (1) (2020) 303-310.

[31] M. Mata-Zamora, J. Saniger, Thermal evolution of porous anodic aluminas: a comparative study, Revista mexicana de física 51 (5) (2005) 502-509. 
[32] J. O'sullivan, J. Hockey, G. Wood, Infra-red spectroscopic study of anodic alumina films, Transactions of the Faraday Society 65 (1969) 535541.

[33] X. Carrier, E. Marceau, J.-F. Lambert, M. Che, Transformations of $\gamma$ alumina in aqueous suspensions: 1 . alumina chemical weathering studied as a function of ph, Journal of Colloid and Interface Science 308 (2) (2007) 429-437. 